\section{Drug use among street children and adolescents: what helps?}

\author{
Uso de drogas entre crianças e adolescentes em \\ situação de rua: o que ajuda?
}

\author{
${ }_{1}$ Departamento de \\ Psicobiologia, Universidade \\ Federal de São Paulo, São \\ Paulo, Brasil. \\ 2 Departamento de Medicina \\ Preventiva, Universidade \\ Federal de São Paulo, \\ São Paulo, Brasil. \\ 3 Instituto de Ciências \\ Humanas e da Informação, \\ Universidade Federal do Rio \\ Grande, Rio Grande, Brasil. \\ 4 Instituto de Psicologia, \\ Universidade Federal do Rio \\ Grande do Sul, Porto Alegre, \\ Brasil. \\ Correspondence \\ Y. G. Moura \\ Unidade de Dependência de \\ Drogas, Departamento de \\ Psicobiologia, Universidade \\ Federal de \\ São Paulo. \\ Rua Napoleão de Barros 1038, \\ São Paulo, SP \\ 04024-003, Brasil. \\ ygmoura@gmail.com
}

\section{Abstract}

The aim of this study was to investigate factors associated to frequent and heavy drug use among street children and adolescents aged 10 to 18 years. A sample of 2,807 street children and adolescents from the 27 Brazilian state capital cities was analyzed. A World Health Organization questionnaire for non-students was adapted for use in Brazil. Data analysis was performed using logistic regression and decision tree models. Factors inversely associated with frequent and heavy drug use were: being age nine to 11 years $(O R=0.1)$; school attendance $(O R=0.3)$; daily time (one to five hours) spent on the streets $(O R=0.3$ and 0.4$) ;$ not sleeping on the streets $(O R=0.4)$; being on the streets for less than one year $(O R=0.4)$; maintenance of some family bonds $(O R=0.5)$; presence on the streets of a family member $(\mathrm{OR}=0.6)$; not suffering domestic violence $(O R=0.6)$; being female $(O R=0.8)$. All of these variables were significant at the $p<0.05$ level. The findings suggest that being younger, having family bonds and engagement in school are important protective factors that affect drug use among this population and should be considered in the formulation of public policies.

Homeless Youth; Street Drugs; Child; Adolescent
Yone Gonçalves de Moura 1

Zila M. Sanchez 2

Emérita S. Opaleye 1

Lucas Neiva-Silva 3

Silvia H. Koller 4

Ana R. Noto 1

\section{Introduction}

The phrase street children and adolescents has been used to refer to a population of youngsters that, alone or in groups, perform informal activities such as doing odd jobs, begging, wandering, and other behavior necessary for their own or their family's survival. In this study, street children and adolescents are defined as those who live, work or spend long periods of time on the street without parental or guardian supervision. Many circumstances may lead children and adolescents to leave their homes, such as family problems and low socioeconomic status. However, in Brazil, it is common to meet adolescents who spend the day on the streets and return to their home and family at night 1 .

Several countries have reported an increase in this population, especially of youngsters between the ages of 15 and 17 years 2,3,4,5,6,7. Frequent or heavy drug use as well as buying and selling of drugs are common behavior in this population ${ }^{3,8}$.

Levels of high-risk behavior among street adolescents present serious consequences. There are reports of early sexuality, the development of sexually transmitted diseases and other infectious diseases, unwanted pregnancy, suicide and physical and mental health problems within this population 7,9 . These problems are intensified by frequent or heavy drug use. Frequent use is defined as using one or more substances 4 to 19 
days a month, while the use of a substance more than 20 days a month is considered to be heavy use 10 .

Studies of this population in other countries have been performed to investigate the factors associated with substance use. These factors include parental drug use, lack of integration into school activities, difficulties associated with educating children in face of new challenges and changes to the traditional family structure, domestic violence and peer pressure 2,3,4,11,12,13,14,15,16.

Some studies that investigate the factors associated with drug use among street adolescents highlight that youths that do not use drugs maintain certain bonds with their family, a certain level of engagement in school, have not suffered domestic violence, spend less time (daily and total number of years) on the streets, and/or form social networks 6,17 . The adversities that homeless adolescents must often face, such as protecting themselves from hunger, cold or domestic violence, combined with a lack of support, parental or guardian supervision and easy access to various substances, predispose them to frequent and heavy drug use 8,18.

Exploring patterns of drug use contributes to the detection of risk behavior in this population. Understanding the factors associated with drug use among Brazilian street children and adolescents is also important to provide a basis for the creation and implementation of effective preventive public policies aimed at this population.

Therefore, the objective of the current study was to investigate the factors associated with frequent and heavy drug use among street children and adolescents from 27 Brazilian state capital cities. Based on the literature investigated, we hypothesized that frequent or heavy drug use is associated with factors related to a greater exposure to street culture, as well as factors related to family bonds and engagement in school.

\section{Methods}

\section{Sample}

The target population consisted of street children and adolescents (both living on the streets or just spending some daily time on the streets) in the 27 state capitals of Brazil. The sample of this study was made up of 2,807 street children and adolescents between the ages of 10 and 18 years (equivalent to the total number of street children and adolescents frequenting 93 care centers in the 27 capitals $(3,028)$ after losses (n $=221,7.3 \%$ ). Losses occurred mainly because of the following reasons: adolescents refused to participated in interviews $(n=133)$ because they preferred not to interrupt their leisure activities; some interviews were postponed and it was not possible to locate the respondent at a future date ( $\mathrm{n}=45$ ); and due to incomplete or inconsistent questionnaires $(n=43)$.

The youth were receiving support from governmental and non-governmental social welfare organizations offering care, food, hygiene and leisure and educational activities. Some of these service providers operate directly in the streets in an attempt to reach the street youth population not already under the auspices of an organization. Due to the lack of official data, most of these care centers were mapped in each capital using snowball sampling 19 until saturation was reached. Among the 94 mapped care centers, only one refused to participate in this study; therefore, the sample was composed of street youth linked to 93 open care centers 20.

All street children and adolescents who frequented the care centers during a week-long period were invited to participate. A period of one week was chosen as the smallest interval of time necessary to guarantee the inclusion of all routine activities at the open care centers. This period included all opening hours (morning, afternoon and evening/night) within seven sequential days.

The following exclusion criteria were employed: pronounced behavioral disturbances, cognitive impairment (difficulty understanding questions) and auditory or verbal dysfunction (difficulty in communicating). Further criteria were also used for postponement of interviews: drug intoxication, aggressive behavior or participation in institutional activities at the moment of recruitment (soccer, painting and others).

\section{Study design}

The study comprised a national cross-sectional survey of children and adolescents who received assistance from specific social welfare organizations in 27 Brazilian state capitals 20,21.

\section{Measures and data collection}

Data was collected between July and December 2003 by means of a structured interview based on a questionnaire.

Interviews lasted 30 minutes and were conducted privately and anonymously. Other ethical safeguards were employed: information about the objective of the study was provided to the interviewee, informed consent, confidentiality, and liberty to interrupt the interview. 
Interviewers in 27 capitals received structured training (meetings, classes, and video demonstrations), received orientation on how to conduct interviews and write down answers and were supervised by the research coordinators throughout the data collection process.

We used a questionnaire proposed by the World Health Organization (WHO) for a non-student youth population 10, adapted for use in Brazilian studies 22,23 . The survey included questions on a wide range of topics, such as demographic characteristics, family bonds, school attendance, child abuse and domestic violence, life on the streets and patterns of drug use. The measures used in the present study are described below.

\section{Participant's characteristics}

Questions about age, gender, social factors, such as school attendance, family bonds and domestic violence, were included. School attendance was considered positive if the participant was attending school at the time of the survey. Nonattendance was characterized by children who had never been to school or had dropped out.

Street children do not necessarily live on the street. We therefore asked if the child lived with their family in order to obtain an understanding of their family bonds. An adolescent was considered to have experienced domestic violence if one of the following circumstances was confirmed in the family environment during his or her lifetime: received a punch, slap or push; was assaulted with an object (piece of wood, cigarette butt, etc.), was assaulted with a weapon; was fondled or kissed, or forced to have sex.

\section{Exposure to street culture}

To identify significant factors regarding their life on the streets and to subsequently assess which factors were associated with drug use, adolescents were asked how much time they spent on the streets (in hours per day), within the following four categories: from one to two hours, from three to four hours, from six to eight hours and more than eight hours. Additionally, respondents were asked about how long (in months and years) they had been on the streets. The answers were recorded in one of three categories: up to one year, from one to five years and more than five years. Furthermore, the following question was asked to assess whether or not the presence of a family member with the adolescent on the streets interfered in his or her drug use: "Who do you spend your time with on the streets?". The possible answers were: alone, with a friend or colleague, father, mother or sibling. A family member was considered present if he or she gave one of the last three answers. For the purpose of assessing whether an adolescent had recently slept on the streets, we inquired as to where they had slept during the last month, with the following possible answers: on the streets, at a relative's or friend's house, in a welfare organization's facilities, other.

\section{Substance use}

To assess substance use, we asked about lifetime use of alcohol, tobacco, cannabis, inhalants, use of medicines for non-medical purposes, cocaine and crack.

We asked specifically about three kinds of medicines that, based on previous studies, we knew were more commonly used among street youth in Brazil: benzydamine, trihexyphenidyl and flunitrazepam 22. For each drug where a yes answer was given, the following questions were asked: the youth's age when he or she first used the drug (open question); if the youth had used the drug in the last year (no/yes), if the youth had used the drug in the previous month (no/yes) and frequency of use during the previous month (from one to three days, from four to 19 days and 20 or more days). Frequent use was defined as between 4 and 19 days and heavy use was defined as 20 days or more. An adolescent was considered to be a frequent or heavy drug user if he or she reported frequent or heavy consumption of at least one of the substances cited in the month prior to the interview.

\section{Data analysis}

The questionnaires were individually examined in order to critically analyze internal consistency and any questionnaires with inconsistencies were excluded. Bivariate analysis was performed using the chi-square test to compare factors associated to non-drug use and frequent or heavy drug use. Furthermore, a decision tree (exhaustive CHAID) was calculated to identify the factor most associated with drug use. Decision trees are used as a visual and analytical decision support tool, where the expected values of competing alternatives are calculated and presented as a treelike graph of decisions and their possible consequences, including chance event outcomes (in our case: being a frequent or heavy drug user) 24 . A logistic regression model was used to measure the strength of the association of the independent variables in predicting frequent or heavy drug use, by inserting the same variables used in the bivariate analyses. The significance level was set at $5 \%$ and the Hosmer \& Lemeshow 25 test was 
used to evaluate the goodness-of-fit of the logistic regression model. All statistical analyses were performed using the software SPSS version 17.0 (SPSS Inc., Chicago, USA).

\section{Results}

Frequent or heavy drug use was reported by $47.7 \%$ of the interviewees $(n=1,338)$. Drug use according to substance type is presented in Figure 1 . Tobacco use was mentioned by $37.9 \%$ of the interviewees ( $\mathrm{n}=2,807$ ), followed by inhalants (23.3\%), alcohol (22\%) and marijuana (19.5\%). Many adolescents reported using more than one substance and $74.2 \%$ had used more than one drug in the last year.

A segmentation analysis of the tree diagram (exhaustive CHAID) was performed using the variables presented in Table 1, in order to identify the profile of frequent or heavy drug users. These results are presented in Figure 2.

Table 1 shows that a significantly high percentage of participants with the following characteristics did not engage in frequent or heavy drug use: female; age between nine and 14 years; had been on the streets for less than one year; spent from one to eight hours a day on the street with a family member present; did not sleep on the street; had family bonds; attended school; and did not suffer from domestic violence.

In Figure 2, the sample was initially divided according to the variable "family bonds" and then according to "school attendance". Node 6 contains $49.9 \%(n=1,402)$ of the initial sample and is formed by the participants that had family bonds and attended school. We observed that $79.6 \%$ of the participants in this group $(n=1,116)$ were not frequent or heavy drug users. Node 6 was then segmented according to the variable "time spent on the streets". Node 10 includes participants that had family bonds, attended school, and that spent from 1 to 5 hours a day on the streets; $84.9 \%$ of this group ( $n=919)$, were not frequent or heavy drug users. The opposite can be observed in node 3 , which is composed of participants that had no family bonds and who did not attend school. This group represents $25.7 \%$ of the total sample and contains $86.4 \%$ of the frequent or heavy drug users.

We conclude that, of the total number of participants who were not frequent or heavy drug users ( $n=1,469), 75.9 \%$ ( $n=1,116)$ had family bonds and attended school (node 6) and 53.1\% ( $\mathrm{n}=781$ ) had family bonds, attended school and spent 1 to 5 hours a day on the streets (node 10). These profiles are significantly different from those of the remaining sub-groups.

Figure 1

Distribution by type of substance used among the 1,338 participants that reported frequent or heavy drug use.

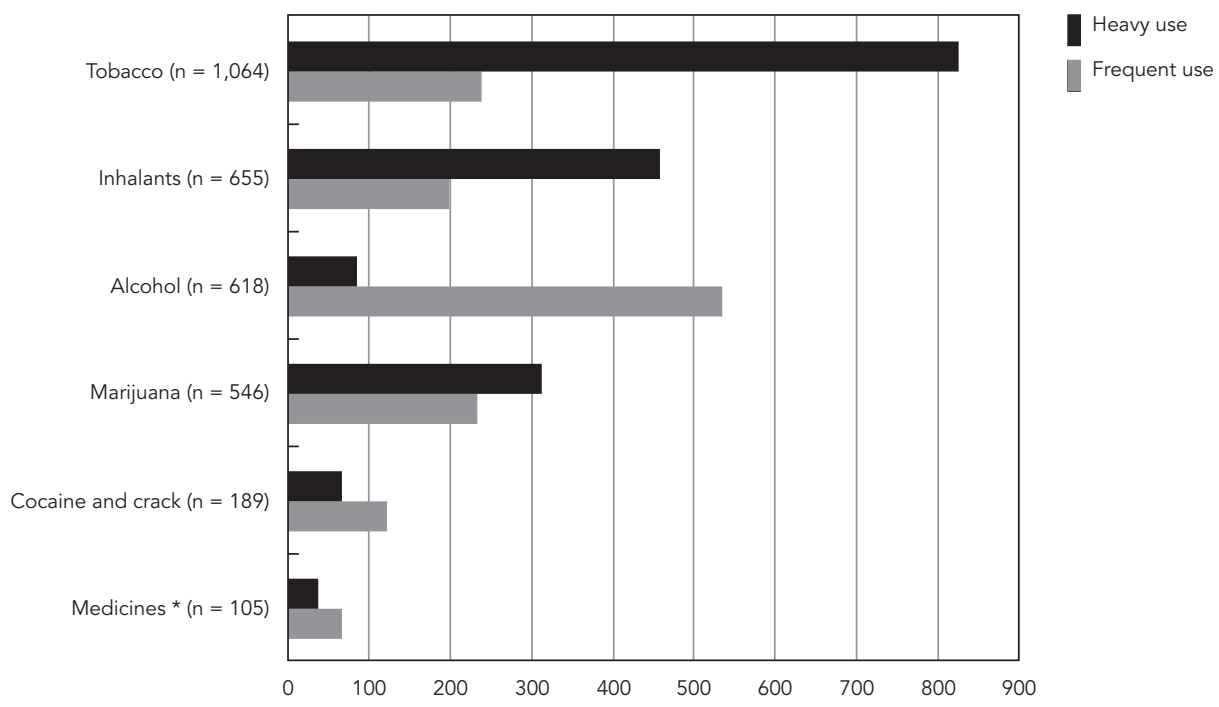

* Medicines: benzydamine, trihexyphenidyl and flunitrazepan. 
Variables studied to evaluate the association with the presence or absence of frequent or heavy drug use among the 2,807 interviewees.

\begin{tabular}{|c|c|c|c|c|c|}
\hline \multirow[t]{2}{*}{ Any drug } & \multicolumn{2}{|c|}{ Non frequent or heavy use } & \multicolumn{2}{|c|}{ Frequent or heavy use } & \multirow[t]{2}{*}{ Total * } \\
\hline & $\mathrm{n}$ & $\%$ & n & $\%$ & \\
\hline \multicolumn{6}{|l|}{ Gender } \\
\hline Male & 1,058 & 49.9 & 1,062 & 50.1 & 2,120 \\
\hline Female & 411 & 59.8 & 276 & 40.2 & 687 \\
\hline \multicolumn{6}{|l|}{ Age (years) } \\
\hline $9-11$ & 362 & 86.6 & 56 & 13.4 & 418 \\
\hline $12-14$ & 620 & 59.2 & 427 & 40.8 & 1,047 \\
\hline $15-18$ & 485 & 36.3 & 852 & 63.7 & 1,337 \\
\hline \multicolumn{6}{|c|}{ Years on the streets (years) } \\
\hline$<1^{\star *}$ & 585 & 68.6 & 268 & 31.4 & 853 \\
\hline $1-5$ & 644 & 50.2 & 640 & 49.8 & 1,284 \\
\hline$>5^{* * *}$ & 142 & 27.0 & 384 & 73.0 & 526 \\
\hline \multicolumn{6}{|c|}{ Time spent on the streets (hours on a daily basis) } \\
\hline $1-2$ & 245 & 84.5 & 45 & 15.5 & 290 \\
\hline $3-5$ & 647 & 76.2 & 202 & 23.8 & 849 \\
\hline $6-8$ & 332 & 58.9 & 232 & 41.1 & 564 \\
\hline$\geq 8$ & 241 & 22.0 & 855 & 78.0 & 1,096 \\
\hline \multicolumn{6}{|c|}{ Sleeping on the street } \\
\hline No & 1,256 & 70.4 & 528 & 29.6 & 1,784 \\
\hline Yes & 213 & 20.8 & 810 & 79.2 & 1,023 \\
\hline \multicolumn{6}{|c|}{ Staying with a family member } \\
\hline No & 1,085 & 47.3 & 1,209 & 52.7 & 2,294 \\
\hline Yes & 384 & 74.9 & 129 & 25.1 & 513 \\
\hline \multicolumn{6}{|c|}{ Family bonds } \\
\hline No & 161 & 18.2 & 725 & 81.8 & 886 \\
\hline Yes & 1,308 & 68.1 & 613 & 31.9 & 1,921 \\
\hline \multicolumn{6}{|c|}{ School attendance } \\
\hline No & 290 & 23.3 & 952 & 76.7 & 1,242 \\
\hline Yes & 1,179 & 75.3 & 386 & 24.7 & 1,565 \\
\hline \multicolumn{6}{|c|}{ Domestic violence } \\
\hline No & 1,102 & 59.6 & 746 & 40.4 & 1,848 \\
\hline Yes & 367 & 38.3 & 592 & 61.7 & 959 \\
\hline
\end{tabular}

Note: all of the cross variables presented $p<0,0001$

* Some categories present missing data and do not sum up to $100 \%$;

All categories presented significant differences from each at the $5 \%$ level after adjusting standardized resuduals. ${ }^{\star \star}$ and ${ }^{\star \star \star}$ presented significant diferrences at the $5 \%$ level after adjusting standardized residuals.

The logistic regression presented in Table 2 shows that all of the evaluated variables reached significance, thus determining that the model required only one step. Reference categories for each variable were chosen so as to create a model that focused on possible protection factors where a lower than 1 odds ratio represents protection from frequent or heavy drug use.

Using the logistic regression model, the factor with the strongest inverse association with frequent or heavy drug use was age between 10 and 11 years. Children of this age are up to $90 \%$ ( $\mathrm{p}<0.001$ ) less likely to practice this behavior than those aged between 15 and 18 years. When evaluating adolescents aged between 12 and 14 years, an increase in drug use was found, shown by an increase in the odds ratios. This demonstrates that this group is $50 \%$ less likely to be involved in frequent or heavy drug use $(\mathrm{p}<0.001)$ than their older counterparts.

Another factor with a strong inverse association with frequent or heavy drug use is school 
Figure 2

Tree diagram resulting from the segmentation analysis of the variable "frequent or heavy drug use".

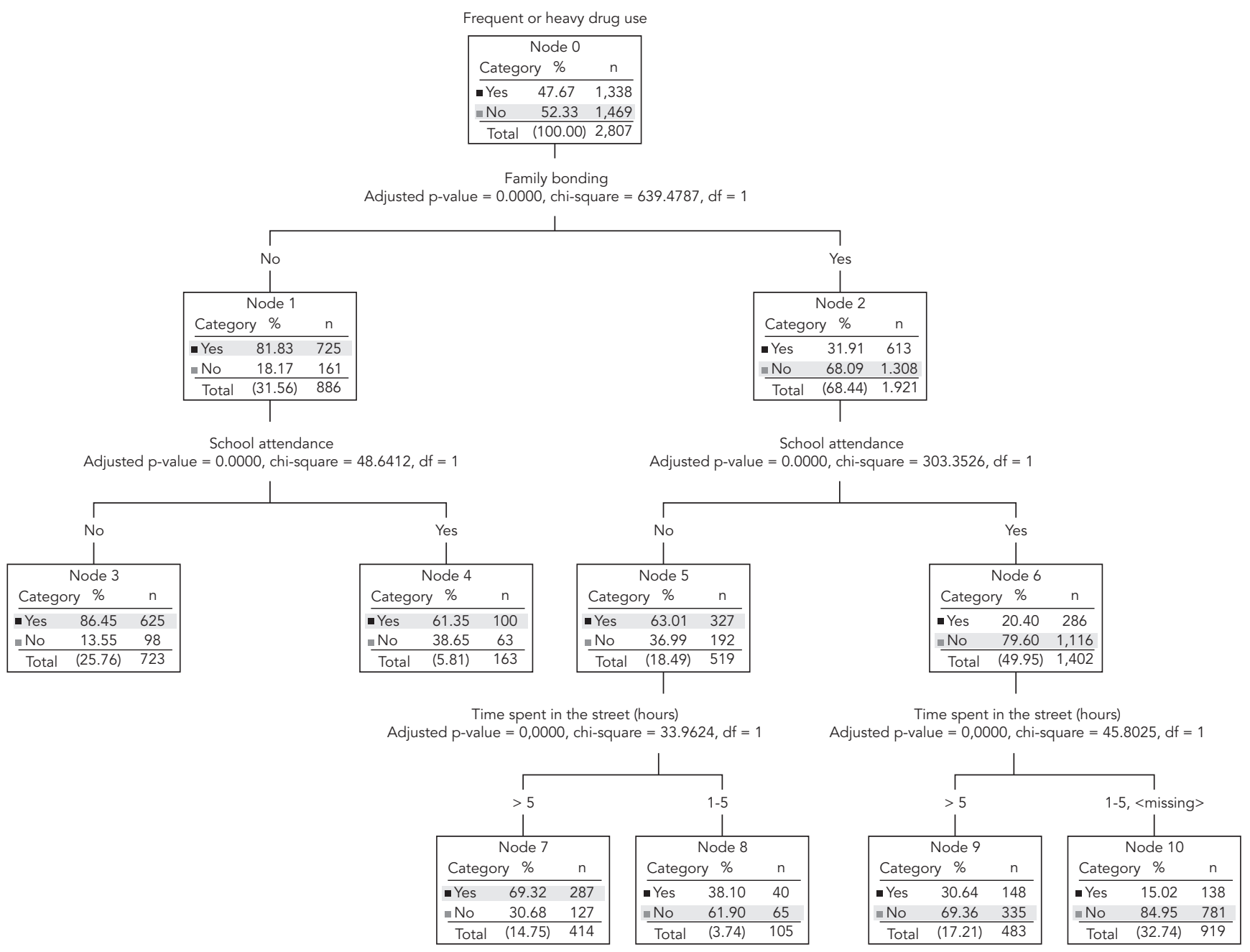

attendance; interviewees that were attending school were $70 \%$ ( $\mathrm{p}<0.001$ ) less likely to be frequent or heavy drug users. Regarding time spent on the street (using the category more than 8 hours as a reference), results demonstrated that the more time spent on the street, the greater the likelihood of being a frequent or heavy drug user. Adolescents that spent between one and five hours a day on the streets were approximately $70 \%$ ( $\mathrm{p}<0.001$ ) less likely to be frequent or heavy drug user than those that spent more than eight hours a day on the streets.

Not sleeping on the street also appears to be a protective factor. Those adolescents that did not sleep on the streets were nearly $60 \%$ (p < 0.001 ) less likely to be frequent or heavy drug users.

The total time, in years, spent on the streets also appears to be associated with drug use. According to the model, adolescents that had been on the streets for less than a year were $60 \%$ $(\mathrm{p}<0.001)$ less likely to be frequent or heavy drug users than those who had been on the streets for more than a year.

The family variables were also significant in the model. Having family bonds and being on the streets with a family member were inversely associated with drug use $(\mathrm{OR}=0.5 ; \mathrm{p}<0.001$ and $\mathrm{OR}=0.6 ; \mathrm{p}=0.001$, respectively). Further- 
Logistic regression for family variables, street and school contexts associated with frequent and heavy drug use.

\begin{tabular}{|c|c|c|c|c|}
\hline Variables in the equation & p-value & OR & $95 \% \mathrm{Cl}$ minimum & $95 \% \mathrm{Cl}$ maximum \\
\hline Age (years) & $<0.001$ & & & \\
\hline $10-11$ & $<0.001$ & 0.124 & 0.083 & 0.184 \\
\hline $12-14$ & $<0.001$ & 0.489 & 0.392 & 0.610 \\
\hline $15-18$ & Reference & & & \\
\hline Attending school (yes) & $<0.001$ & 0.342 & 0.269 & 0.433 \\
\hline Time spent on streets (hours on a daily basis) & $<0.001$ & & & \\
\hline $1-2$ & $<0.001$ & 0.324 & 0.211 & 0.497 \\
\hline $3-5$ & $<0.001$ & 0.364 & 0.274 & 0.483 \\
\hline $6-8$ & $<0.001$ & 0.596 & 0.449 & 0.90 \\
\hline$\geq 8$ & Reference & & & \\
\hline Sleeping on the streets (no) & $<0.001$ & 0.404 & 0.314 & 0.521 \\
\hline Years on the streets & $<0.001$ & & & \\
\hline$<1$ & $<0.001$ & 0.419 & 0.305 & 0.574 \\
\hline $1-5$ & 0.020 & 0.714 & 0.537 & 0.949 \\
\hline$\geq 5$ & Reference & & & \\
\hline Family bonds (yes) & $<0.001$ & 0.472 & 0.362 & 0.615 \\
\hline Presence of a family member (yes) & 0.001 & 0.609 & 0.458 & 0.809 \\
\hline Domestic violence (no) & $<0.001$ & 0.659 & 0.527 & 0.825 \\
\hline Gender (female) & 0.032 & 0.761 & 0.592 & 0.977 \\
\hline Constant & 0.000 & 34.663 & & \\
\hline
\end{tabular}

95\% Cl: 95\% confidence interval; OR: odds ratio.

Note: R2 Nagelkerke = 0.489; -2LL = 2384.320; Hosmer-Lemeshow goodness of fit p-value $=0.265$. Cut-off: $46 \%$; sensitivity: $80 \%$; specificity: $80 \%$.

more, the interviewees that stated that they had not suffered from domestic violence were $40 \%$ ( $p<0.001$ ) less likely to engage in frequent or heavy drug use.

Finally, gender, although significant in the model, appears to have the weakest association given that the $\mathrm{p}$-value $(\mathrm{p}=0.032)$ was the closest to the established limit for significance.

The Hosmer \& Lemeshow 25 test showed a goodness-of-fit for the model adjustment ( $p=0.265$ ), obtaining a sensitivity of $80 \%$ and a specificity of $80 \%$ with a cut-off of $46 \%$.

\section{Discussion}

The results observed by this study point to several factors that are inversely associated to frequent or heavy drug use. These findings may aid in the development of interventions aimed at street children and adolescents. Some authors have demonstrated that there are important stages in childhood and adolescence in which these children and adolescents are more sensitive to interventions. Our findings corroborate results from other countries concerning a population excluded from basic rights that are fully necessary to their development 4,6,8,9,11,18,26. Accordingly, the findings from the current study present evidence of important circumstances that should be taken into account when formulating possible interventions aimed at this population.

The strongest association with drug use observed by this study was the variable age. Data suggests that, although children are introduced to the streets at a surprisingly early age, this in itself may serve as an important protective factor, since at this age children are less likely to become engrained in street culture and, consequently, are less likely to engage in frequent or heavy use of drugs. This type of drug use may be associated with the need to fit in to street culture in order to be part of a group or in the search for survival. Care centers that carry out activities with this population, focusing specifically on the identification of younger children, are an important source of information and a valuable resource for prevention programs 18 . In a study on the general population of adolescents, childhood was identified as a phase that deserves particular 
attention in actions aimed at the prevention of the risk factors that are characteristic of adolescent substance use 12 .

School attendance appeared in the logistic regression model as a factor inversely associated with frequent and heavy drug use. Although paradoxical, we encountered street adolescents who were also attending school. This engagement with school appears to reduce the adolescent's involvement with street culture, which may consequently turn the youth away from drug use. To attend school, interact and learn, adolescents cannot be intoxicated and must maintain at least a minimal level of hygiene, clothes and school supplies. If street adolescents can comply with these requirements, they may be able to maintain an adequate level of engagement with school. School plays a role not only as a source of information and education but also as a social network that can prevent school evasion and the lack of interest for school as a whole. Certain studies show that the disengagement from school is a strong negative factor for these youth $3,4,15$.

The present study also showed that the likelihood of frequent or heavy drug use decreases with a reduction in the length of time the adolescent is exposed to the streets. The data suggests that protection from heavy drug use is greater for an adolescent that spends between one and five hours on the streets than one that spends more than eight hours a day on the streets, corroborating the findings of Milburn et al. 17. Less time exposed to the streets means less contact with street culture, peer pressure and, consequently, frequent or heavy drug use. It is also suggested that spending less time on the streets during the day may be associated with spending more time at school or under the supervision of social support organizations, thus decreasing the time available for drug use.

Likewise, not sleeping on the streets results in less time spent on the streets. This decreases the youth's exposure to inclement weather, the lack of an adequate place to sleep, easy access to the traffic and sale of drugs and, especially, peer pressure. As demonstrated in observational studies, these are the main factors influencing substance use 8,27 .

One of the most disputed protective factors in the literature are family bonds $13,26,28$. In the current study, both family bonds and presence of a family member together with the adolescent were inversely associated with frequent or heavy drug use. This data shows that, the presence of a family is important for children exposed to a street environment, making them less prone to drug use. The relationship of some adolescents with their family is limited to just sleeping at home, after spending a short period of time or the whole day on the streets. However, the presence of a family member sharing his or her life on the streets may fortify their bonds, and this could explain why this aspect appears as a protective factor in this study.

The family is the primary social safety net for children. When it is connected to a social network of external resources, such as the community, school, health and other services, the unit is strengthened and the family is able to maintain its bonds even in the face of difficulties inherent to social exclusion. An important role of professionals involved with this population is therefore to understand and intervene with the family's social network to prevent migration to the streets 17,29 .

The absence of domestic violence was also a protective factor for these individuals. In the proposed model, freedom from domestic violence decreases the chance of frequent or heavy drug use group by $40 \%$, while family bonding decreases chances by $50 \%$, with the same p-value. This seems contradictory but perhaps in this specific group, having family bonds is more important, even if precarious, than not having any at all. Adolescents who have been exposed to all forms of exclusion from an early age appear to accept the family bonds even when accompanied by violence. In other words, these kind of bonds are seen as better than nothing at all. The evidence of this acceptance includes the perpetuation of the violence witnessed with their parents in the adolescent's own interpersonal adult relationships 28.

Although research has shown that there are a greater number of male street adolescents 6,9,30, gender does not seem to influence frequent or heavy drug use. Girls in street circumstances are of the same group and are therefore subject to similar risks when it comes to frequent or heavy drug use. Some studies have suggested that for both male and female street adolescents, the variety of problems they faced before leaving home is so great that gender is not a differential in terms of coping with the difficulties confronted on the street 3,9 . Due to the chronic nature of street culture, adolescents encounter the same risk behaviors and inherent dangers of life on the street independent of gender 17 .

These and findings from related research can aid professionals that work directly on a daily basis with street children. Certain studies demonstrate that these professionals work under difficult circumstances, including the daily intoxication of adolescents who engage in frequent and heavy drug use 29. 
Despite the results, this study has some limitations. To compose the sample, only street children and adolescents linked to social support organizations were considered. Thus, street youth that were not frequenting such an organization's facilities during data collection did not participate in the study. Care should therefore be taken when extrapolating our findings to these groups. Furthermore, open service centers were mapped using snowball sampling as there is no official government record of their existence and, therefore, some open service centers may have been overlooked. Also, it was not possible to interview certain adolescents because they were clearly under the effects of substances or showed aggressive behavior towards the interviewer. This is also highlighted as a limitation of our study due to the effect their participation would have had on prevalence.

Furthermore, a cross-sectional study does not lend itself to establishing causality; therefore, the associations between drug use and the other factors should be not be treated as causes and consequences. Finally, the answers that were obtained are consumption reports rather than measures, which could reduce the reliability of the data.

\section{Conclusion}

Several factors are inversely associated with frequent and heavy drug use including: being age nine to 11 years; school attendance; reduced exposure to street culture; family bonds; and not having suffered domestic violence. These variables have been confirmed as important protective factors against frequent or heavy drug use. These factors should therefore be taken into consideration in the formulation of public policies aimed at this population, emphasizing specific moments and stages in development at which the adolescent is more open to intervention.

\section{Resumo}

O objetivo do estudo foi verificar fatores associados ao uso frequente e pesado de drogas entre adolescentes em situação de rua no Brasil. Estudo transversal com amostra representativa nacional de 2.807 crianças e adolescentes (10-18 anos). Foi usado um questionário da Organização Mundial da Saúde adaptado para o Brasil e análise dos dados, modelo de regressão logística. Fatores inversamente associados ao uso frequente e pesado de drogas: faixa etária entre 9-11 anos $(O R=0,1)$; frequentar escola $(O R=0,3)$; permanecer entre 1 e 5 horas na rua $(O R=0,3$ e 0,4); não dormir na rua $(O R=0,4)$; estar na rua há menos de um ano $(\mathrm{OR}=0,4)$; manter algum vínculo familiar $(O R=$ $0,5)$; permanecer na rua com algum membro da família $(O R=0,6)$; não ter sofrido violência doméstica $(\mathrm{OR}=0,6)$; gênero feminino $(\mathrm{OR}=0,8)$. Todas essas variáveis apresentaram $p<0,05$. Os achados sugerem que ser mais jovem, ficar menos tempo na rua e manter vínculos com escola e família são importantes fatores de proteção para essa população quanto ao uso frequente e pesado de drogas. Esses são fatores importantes na formulação de políticas públicas para essa população.

Menores de Rua; Drogas Ilícitas; Criança; Adolescente

\section{Contributors}

Y. G. Moura contributed towards project design, data collection and analysis, and the drafting and revision of this article. Z. M. Sanchez was responsible for data analysis and contributed to the drafting and revision of this article. E. S. Opaleye contributed towards data analysis and the drafting and revision of this article. L. Neiva-Silva contributed towards project design and data collection, was responsible for data analysis and the revision of this article. S. H. Koller contributed towards project design and data collection and the revision of this article. A. R. Noto contributed towards project design and data collection and the drafting and revision of this article.

\section{Acknowledgments}

The authors acknowledge and are grateful to AFIP and CEBRID. 


\section{References}

1. Moura YG, Sanchez ZM, Noto AR. Diversity of contexts in drug use among street adolescents. Qual Health Res 2010; 20:1241-53.

2. Belfer ML, Rohde LA. Child and adolescent mental health in Latin America and the Caribbean: problems, progress, and policy research. Rev Panam Salud Pública 2005; 18:359-65.

3. Carvalho FT, Neiva-Silva L, Ramos MC, Evans J, Koller SH, Piccini CA, et al. Sexual and drug use risk behaviors among children and youth in street circumstances in Porto Alegre, Brazil. AIDS Behav 2006; 10(4 Suppl):S57-66.

4. Kliewer W, Lenn Murrelle MSPH. Risk and protective factors for adolescent substance use: findings from a study in selected Central American countries. J Adolesc Health 2007; 40:448-55.

5. Marshall BDL, Kerr T, Shoveller JA, Patterson TL, Buxton JA, Wood E. Homelessness and unstable housing associated with an increased risk of HIV and STI transmission among street-involved youth. Health Place 2009; 15:753-60.

6. Rachlis BS, Wood E, Zjanga R, Montaner JSG, Kerr T. High rates of homelessness among a cohort of street-involved youth. Health Place 2009; 15:10-7.

7. Towe VL, ulHasan S, Zafar ST, Sherman SG. Street life and drug risk behaviors associated with exchanging sex among male street children in Lahore, Pakistan. J Adolesc Health 2009; 44:222-8.

8. Auerswald CL, Eyre SL. Youth homelessness in San Francisco: a life cycle approach. Soc Sci Med 2002; 54:1497-512.

9. Gwadz MV, Gostnell K, Smolenski C, Willis B, Nish D, Nolan TC, et al. The initiation of homeless youth into street economy. J Adolesc 2009; 32:357-77.

10. Smart RG, Arif A, Hughes PH, Medina-Mora MH, Navartnam V, Varma VK, et al. Drug use among non-student youth. Geneva: World Health Organization; 1981.

11. Schinke SP, Fang L, Kristin CA, Cole MS. Substance use among early adolescent girls: risk and protective factors. J Adolesc Health 2008; 43:191-4.

12. Cleveland MJ, Feinberg ME, Bontempo DE, Greenberg MT. The role of risk and protective factors in substance use across adolescence. J Adolesc Health 2008; 43:157-64.

13. Olley BO. Social and health behaviors in youth of the streets of Ibadan, Nigéria. Child Abuse Negl 2006; 30:271-82.

14. Montauk SL. The homeless in America: adapting your practice. Am Fam Physician 2006; 74:1132-8.

15. Martijn C, Sharpe L. Pathways to youth homelessness. Soc Sci Med 2006; 62:1-12.

16. Aderinto AA. Social correlates and coping measures of street-children: a comparative study of street and non-street children in South-Western Nigeria. Child Abuse Negl 2000; 24:1199-213.
17. Milburn N, Li-Jung L, Lee S-J, Rotheram-Borus MJ, Rosenthal D, Mallett S, et al. Who is doing well? A typology of newly homeless adolescents. J Community Psychol 2009; 37:135-47.

18. Kudrati M, Plumier ML, Yousif NDEH. Children of the sug: a study of the daily lives of street children in Khartoum, Sudan, with intervention recommendations. Child Abuse Negl 2008; 32:439-48.

19. Biernacki P, Waldorf D. Snowball sampling-problems and techniques of chain referral sampling. Sociol Methods Res 1981; 10:141-63.

20. Noto AR, Galduróz JCF, Nappo SA, Carlini CMA, Moura YG, Fonseca AM, et al. Levantamento nacional sobre o uso de drogas entre crianças e adolescentes em situação de rua nas 27 capitais brasileiras. São Paulo: Centro Brasileiro de Informações sobre Drogas Psicotrópicas; 2003.

21. Opaleye ES, Noto AR, Sanchez ZM, Moura YG, Galduroz JC, Carlini EA. Recreational use of benzydamine as a hallucinogen among street youth in Brazil. Rev Bras Psiquiatr 2009; 31:208-13.

22. Noto AR, Nappo SA, Galduróz JCF, Mattei R, Carlini EA. Use of drugs among street children in Brazil. J Psychoactive Drugs 1997; 29:185-92.

23. Carlini-Cotrim B, Carlini EA. The use of solvents and other drugs among homeless and destitute children living in the city streets of Sao Paulo, Brazil. Social Pharmacology 1988; 2:51-62.

24. Cha S-H, Tappert CC. A genetic algorithm for constructing compact binary decision trees. Journal of Pattern Recognition Research 2009; 4:1-13.

25. Hosmer DW, Lemeshow S. Applied logistic regression. 2nd Ed. New York: John Wiley \& Sons; 2001.

26. Balachova TN, Bonner BL, Levy S. Street children in Russia: steps to prevention. Int J Soc Welf 2009; 18:27-44.

27. Hickler B, Auerswald CL. The worlds of homeless white and African American youth in San Francisco, California: a cultural epidemiological comparison. Soc Sci Med 2009; 68:824-31.

28. Basso RVJ, Graham J, Pelech W, DeYoung T, Cardey R. Children's street connections in a Canadian community. Int J Offender Ther Comp Criminol 2004; 48:189-202.

29. Rew L, Rochlen AB, Murphey C. Health educators' perceptions of a sexual health intervention for homeless adolescents. Patient Educ Couns 2008; 72:71-7.

30. Tevendale HD, Lightfoot M, Slocum SL. Individual and environmental protective factors for risky sexaul behavior among homeless youth: an exploration of gender. AIDS Behav 2009; 13:154-64.

Submitted on 30/Mar/2011

Final version resubmitted on $27 / \mathrm{Feb} / 2012$

Approved on 19/Mar/2012 